\title{
AN INTEGRATIVE PROPOSAL TO TEACH \\ THE PRAGMATICS OF PHATIC COMMUNION IN ESL CLASSES
}

\begin{abstract}
Learners of English may have problems or make mistakes when engaging in phatic communion, as its use requires a meta-pragmatic awareness of a wide range of complex and subtle issues, such as when and with whom to engage in it, the underlying reasons to do so, the types of phatic tokens that may be exchanged, the topics that such tokens may address, or potential effects achievable. Although many didactic materials implicitly deal with some elements related to phatic communion, they do not include it as an independent topic, nor do they neatly define it, distinguish its different manifestations or address its socio-cultural peculiarities. For this reason, this paper suggests a methodological proposal to teach the pragmatics of phatic communion and raise learners' meta-pragmatic awareness. Based on an approach to teach the pragmatics of specific L2 aspects (Martínez Flor and Usó Juan 2006), this proposal integrates relevant findings about phatic communion from pragmatics and other neighbouring disciplines, combines different approaches to teach intercultural pragmatic issues in class and includes tasks.
\end{abstract}




\section{Introduction}

Learners of English of diverse proficiency levels may experience performance- and language-related problems, as a consequence of which they deviate from native speakers' standards and expectations when accomplishing speech acts, producing certain types of discourse or participating in conversations (Thomas 1983; Kaur 2011). ${ }^{1}$ Such deviations may result in pragmatic errors, which, though unnoticed in some cases, give rise to funny or anecdotal misunderstandings or even have more serious consequences in others. To be communicatively competent, learners of English must acquire some knowledge and develop the necessary skills that enable them to reach their social and communicative goals, as well as to project their desired identity, by performing adequately in a variety of social or situational contexts.

An area that poses difficulties and challenges to many learners of English is phatic discourse, small talk or phatic communion, i.e. that "[...] language used in free, aimless, social intercourse" (Malinowski 1923: 476), or, in other words, that conversation devoid of relevant factual content but with a great latent significance because it creates, maintains and/or enhances friendly relationships (Burnard 2003: 680). Its presence in many cultures and communities of practice, and hence the assumption that learners could transfer the necessary knowledge and ability to engage in it from their L1 (Kasper and Schmidt 1996; Kasper 1997), might have motivated its neglect in many teaching materials and courses. However, the pragmatics of phatic communion varies across cultures and communities of practice, unveiling differing underlying value systems (Placencia 2004; Sun 2004; Ladegaard 2011). For example, Duda and Parpette (1987) noted that, when engaging in phatic exchanges, learners of French used quite idiosyncratic formulae and made distinct estimations about who could initiate such exchanges, their topics, loci or the amount of talk, which resulted in unwanted interpretations. Likewise, Mugford (2011) has shown that his Mexican learners of 
English did not adhere to L2 norms or practices when engaging in phatic communion. Unaware of the role of status and distance in the target community, on some occasions they made overly personal comments to their teachers, as if talking to very close subjects. On other occasions, they greeted as expected when entering classrooms, but proffered much selfdisclosure or transferred unsuitable L1 idiomatic phatic expressions -e.g. 'fresh as a salad' instead of 'fresh as a daisy' as a reply to a how-are-you question. ${ }^{2}$ This proves that this area of interaction, often regarded as unproblematic, may at times turn out to be risky, treacherous and troublesome, so it deserves pedagogic attention. Indeed, an effective management of small talk in any language requires knowledge of subtle issues, such as when and with whom to engage in it, the underlying reasons and purposes to do so, the topics that can be addressed or the effects achievable.

Pedagogic intervention can certainly improve L2 learners' pragmatic abilities, above all if they are not in direct contact with the L2 or some pragmatic features or nuances are not very salient (Kasper and Rose 1993; Safont Jordá 2005; Ishihara and Cohen 2010). Accordingly, this paper makes a methodological proposal to teach the pragmatics of phatic communion in English. This proposal is based on an approach to teach the pragmatic aspects of English requests and suggestions (Martínez Flor and Usó Juan 2006) insofar as it follows its six-phase structure, but such phases are adapted to cover the most important issues concerning phatic communion. Therefore, this proposal incorporates some of the most relevant findings in this area of human communication contributed from neighbouring disciplines such as sociolinguistics, the ethnography of speaking, discourse and conversation analysis and, obviously, pragmatics. This paper starts by examining how phatic communion is tackled in current English materials.

\section{Phatic communion in ESL materials}


An examination of available ESL materials reveals that phatic communion is hardly included among the functional or discourse issues in most syllabi for levels A1 and A2 (Clandfield 2006, 2007; Hobbs and Keddle 2008), A2-B1 (Kerr 2006), B1 and B2 (Goldstein 2005; Hobbs and Keddle 2006; Kerr and Jones 2006, 2007; Redston and Cunningham 2006, 2007; Soars et al. 2005; Tite et al. 2008; Dellar and Walkley 2010), C1 (Stempleski et al. 2007; Norris 2008; Cunningham and Bell 2009) and C2 (Capel and Sharp 2002; Kenny et al. 2002). ${ }^{3}$ Especially at the lowest levels, these materials include manifestations of phatic communion at the outset and end of conversations (greetings, introductions, farewells, etc.) when addressing specific vocabulary and grammatical structures. However, these only represent ritual acts to establish contact and create a propitious atmosphere for interaction (Laver 1975, 1981; Edmondson and House 1981). Furthermore, at these and other levels, most materials do not neatly delimit phatic communion, nor do they distinguish its different manifestations and socio-cultural peculiarities. At most, they implicitly deal with phatic communion in different activities (listenings, model dialogues, etc.) linked to personal introductions, social gatherings and the discussion of certain topics (daily routines, the city, likes, habits, etc.). Such scarce attention might be due to one prevalent attitude ever since Malinowski (1923) described this area of human social behaviour.

Owing to its alleged triviality, obviousness or meaninglessness, phatic discourse is often regarded as aimed at establishing or maintaining the interactive contact, recognising and acknowledging the presence of others and accommodating them (Abercrombie 1956; Turner 1973; Hudson 1980). Hence, it is associated with purely social or interactive discourse, as opposed to authentically informative or transactional discourse (Scollon and Wong-Scollon 1995). This attitude has marginalised sociality "[...] as a "small' concern" and foregrounded “[...] language for transacting business and other commercial or institutional instrumentalities [...]" (Coupland 2000: 7-8), which surfaces in the emphasis on transactional speech acts 
(requests, invitations, offers, etc.) and discourse types (arguing, giving opinions, debating, etc.) in many didactic materials.

But phatic discourse is a fundamental interactive mechanism for social cohesion and amicability (Holmes 2000; Burnard 2003; Placencia 2004), as it contributes to feelings of involvement, agreement, collegiability or solidarity between interlocutors (Lyons 1968; Silva 1980; Leech 1983; Schneider 1988; Coupland et al. 1992). Like any other communicative practices ingrained in and affected by the sociocultural milieu and the identities of interlocutors, its teaching becomes indispensable because phatic communion displays differences not only across individuals from various backgrounds, but also across smaller communities of practice. Cultural beliefs, norms and tendencies highly influence what may count as talkable topics, when interlocutors will be allowed or expected to engage in small talk, with whom, its outcomes and even the inferences that its (in)felicitous use may trigger (Placencia 2004; Sun 2004; Ladegaard 2011). For this reason, this area of human communication cannot be overlooked in classes on the assumption that learners will cope with it because they succeed to do so in their L1.

The few available English course-books that include phatic communion (O'Dell and Broadhead 2008; Dellar and Walkley 2012 [C1]) place it under the rubric of 'small talk'. Unfortunately, a closer inspection reveals that what students may receive is just exposure to texts and dialogues containing phatic talk, a few hints about the sort of 'ice-breakers' to open or close conversations or to engage in extended phatic dialogues. A case in point is Dellar and Walkley (2012: 99), where phatic communion appears as part of a unit dealing with business and economy. Learners firstly have to listen to a telephone conversation between two colleagues who engage in small talk about 'side-issues'. After a series of awareness-raising questions eliciting previous knowledge about phatic communion and conversational styles, learners have to decide which questions might elicit a series of phatic comments. Next, they 
are proposed to role-play four telephone conversations similar to the initial one, in which they must engage in as much small talk as possible. Except for the awareness-raising questions, learners are neither assisted to deduce nor do they find explicit information about the particulars of phatic communion. Moreover, in accompanying resources teachers cannot find any guidance about what aspects of phatic communion they should deal with, how to do so and why.

Regarding English, at least in the United Kingdom and the United States, research in general and intercultural pragmatics, sociolinguistics, the ethnography of speaking and discourse and conversational analysis has shown that there are well-differentiated types of phatic tokens (Laver 1975; Ventola 1979; Edmondson and House 1981), significant restrictions operating on topic selection (Schneider 1988) and tendencies in the use of phatic utterances on the grounds of specific psycho-social factors (Laver 1975, 1981). In addition, interlocutors can exploit phatic discourse strategically in order to achieve certain effects and its incorrect or unexpected use may have very predictable consequences on social relations (Laver 1975, 1981). Consequently, it is by far more than convenient to develop a researchinformed methodology that takes these findings into account and provides teachers and learners with complete information about the most relevant traits of phatic communion.

Depending on their proficiency level, learners may bring some tacit knowledge of phatic communion from their L1 but still be unable to make informed decisions about its use and contents, or fail at controlling an inventory of pragmalinguistic strategies efficiently. Different instructional approaches -explicit and implicit teaching- seem to facilitate acquisition of relevant L2 pragmatic aspects and contribute to learners' performance (Alcón Soler 2005). Therefore, such methodology should combine those approaches, so that learners can infer underlying rules by themselves after being exposed to input, strengthen previously existing or recently acquired knowledge through explanations and put this knowledge into practice (Rose 
1997; Clennell 1999). Moreover, such methodology must include a wide array of activities dealing with the pragmalinguistic and sociopragmatic features of phatic communion, which, by meeting learners' needs, attitudes and learning styles, may raise their awareness of and skills in this communicative practice.

\section{A methodological proposal to teach the pragmatics of phatic discourse}

Practitioners in interlanguage and instructional pragmatics have suggested different frameworks to teach specific L2 pragmatic aspects, which coincide in some respects. For instance, for teaching speech acts Cohen (2005) combines learning strategies, such as knowing how they work, cross-cultural analysis or observing natives, and use strategies, such as practice in imaginary and real situations and asking natives for feedback. ${ }^{4}$ Usó Juan and Martínez Flor (2008) include exploring target aspects, production and receiving feedback from peers and the teacher. Finally, Kondo (2008) suggests five instructional steps: warmingup or feeling, doing, thinking, understanding and using.

This methodological proposal is based on Martínez Flor and Usó Juan's (2006) proposal to teach English requests and suggestions: the 6Rs Approach. Although this approach was developed for speech acts, this proposal is based on it because it includes all the necessary requisites for learning to take place, namely, input, output and feedback (Swain 1998). Furthermore, its six-phase structure enables the following:

- Arranging contents in well-delimited thematic blocks where teachers and students can concentrate on specific aspects.

- Flexibility at distributing blocks in sessions depending on factors such as time availability and learners' proficiency, needs, difficulties and progress.

- Progressing logically from more general theoretical issues to more specific, and probably complex, practical ones. 
Nevertheless, this proposal accommodates relevant findings about the features, functions, use and effects of phatic communion from different disciplines. This empowers teachers to offer insightful explanations and prepare research-informed tasks which facilitate learners' noticing of these issues. This proposal is intended for use with learners of at least a B1 level, as at this level learners are expected to have already acquired a certain level of fluency, to be able to talk about different topics and accomplish various linguistic functions. Its six phases, whose names are adapted from Martinez Flor and Usó Juan's (2006) work, are explained below.

\subsection{Researching phatic discourse}

Teachers should start by defining phatic communion, explaining where it may appear, commenting on its functions and correcting possible common misconceptions. Defining phatic communion is essential in laying solid foundations upon which subsequent knowledge can be built, above all when many or most learners may ignore what the term denotes. ${ }^{5}$ Explaining when and where it may appear is fundamental in making learners conscious of its ubiquity, as phatic communion is not restricted to conversational margins.

The first definition of this linguistic phenomenon is attributed to anthropologist Malinowski (1923: 476), who characterised it as idle, aimless, irrelevant, but socially important discourse. Learners must understand that phatic communion is ubiquitous and prevalent, a "[...] most human process" (Sun 2004: 1462), which shows up through a plethora of acts like greetings, welcomes, questions about the interlocutors, leave-takes, wish-wells, farewells, compliments about obvious achievements or personal traits, complaints, narrations, chit-chat or comments about trivial things or events (Malinowski 1923: 476-479).

The most frequent conversational contexts where phatic discourse typically appears are openings and closings (Laver 1975), where it surfaces as ritual (Edmondson and House 1981: 98) or formulaic utterances (Kasper 1984; Duda and Parpette 1987). Learners must know that 
at those phases phatic utterances are often organised as adjacency pairs (e.g. Schegloff 1972; Schegloff and Sacks 1973), some of which are so fixed or predictable that they constitute frozen pairs (Hoey 1991). Minimal pairs of ritual phatic acts may be expanded with other phatic questions, comments or remarks that deal with safe topics, thus giving rise to larger phatic sequences (Pavlidou 1994). Teachers should warn learners that the fixation of such stretches somehow favours their phatic interpretation (Kasper 1984; Coupland et al. 1992), precisely because they are not understood as proper first topics (Schegloff and Sacks 1973: 300), but as social niceties that lubricate the beginnings and endings of conversations.

However, phatic discourse cannot be restricted to the fringes of conversations; learners must be alerted that it also appears in the middle of the purely transactional phase as a way to ensure the achievement of interactive goals because of the propitious and friendly atmosphere it creates or maintains (Laver 1975; Coupland et al. 1992; Placencia 2004). Through it, individuals avoid the unpleasant tension that undue silences or getting or sticking excessively to the point may cause, since the former may be perceived as a sign of hostility or bad mood, whilst the latter may be imply disregard for personal relations and commonality. On other occasions still, through phatic communion interlocutors avoid some immediate interactive conflict when carrying out some transaction and restore harmony by creating bonds of union.

Learners should also know that phatic communion favours harmony and amicability at openings because of the working consensus it creates thanks to its functions (Laver 1975):

a) Propitiatory, since it diminishes the potential hostility attributable to silence and frames exchanges as friendly (Placencia 2004).

b) Exploratory, for it implicitly conveys indexical information about interlocutors or, if they know each other beforehand, it confirms previous information. ${ }^{6}$

c) Initiatory, as it ensures interaction by “[...] using emotionally uncontroversial communicative material, and demonstrating [...] signals of cordiality and tentative 
social solidarity" (Laver 1975: 221).

At the closing phase, phatic discourse ensures a future consensus owing to these functions (Laver 1975: 230):

a) Mitigating, inasmuch as it assuages any likely feeling of rejection.

b) Consolidating, as it emphasises the enjoyable quality of encounters, mutual esteem and solidarity, amicability and the continuation of contact.

Finally, within conversations phatic talk creates or maintains a favourable atmosphere by fulfilling these functions (Rosnow 1977: 159-163):

a) Entertaining, insofar as interlocutors do not seek any important purpose, but talk amicably guided by equity and parity.

b) Reinforcing or strengthening previous information, attitudes to and viewpoints about specific events or behaviours with a view to approval, endorsement and sanction.

c) Influencing other interlocutors by means of the dissemination of ideas and points of view about specific matters.

In order to conclude this phase, teachers could encourage learners to provide data of phatic discourse in their L1 or L2 taken from authentic conversations, films, TV or radio programmes in order to apply the knowledge gained. When collecting data, learners may work with the following worksheet, which adapts that proposed by Martínez Flor and Usó Juan (2006: 46) and includes some of Ishihara's (2010a: 45-47) suggestions:

\section{TABLE 1}

\subsection{Reflecting on phatic discourse}

After introducing phatic discourse, learners may be guided to reflect on their L1 and L2 findings. This phase mainly involves implicit instruction, for learners have to analyse remarkable features of the data collected. This process may be aided by awareness-raising 
questions dealing with both the pragmalinguistic and sociopragmatic aspects of phatic discourse, like the following, also based on Martínez Flor and Usó Juan (2006):

\section{TABLE 2}

Next, learners can be exposed to recorded or videotaped dialogues containing samples of L2 phatic discourse (see Section 4.3) and reflect on similar questions. Learners would discuss their observations with peers in order to gain distinct insights and think further about possible divergence between L1 and L2. Focusing on relevant features in authentic examples aids them to connect the pragmalinguistic strategies used, their functions, context-boundness, the role of power, distance or rank of imposition of linguistic acts (Brown and Levinson 1987), their cultural value and possible interpretations by native speakers (Kasper 1997). This sort of activity also makes explicit previous knowledge and stimulates learners to reflect on how phatic communion works, change previous attitudes and develop some preliminary consciousness of the norms underlying its usage. Thus, learners get ready for the acquisition of its pragmatics, as they pay informed attention to salient features; their curiosity, enthusiasm and willingness to invest effort in analysing language and communication by themselves are awaken, and cognitive skills like generalising, connecting, hypothesising and evaluating are stimulated, which facilitate autonomy (Tomlinson 1994).

\subsection{Receiving information about phatic discourse}

The third phase of pedagogic intervention shifts to explicit instruction in order to address in depth two important issues: (i) the different types of phatic utterances and (ii) what the propositional content of those utterances may relate to, i.e. how their topics are selected. Owing to the limitations observed in available materials, this phase aims to instruct learners in some of the complexities of phatic discourse by analysing them thoroughly.

Most works differentiate two categories of phatic utterances: those referring to the spatio- 
temporal setting of conversations (1-4), and those referring to the interlocutors (5-8):

(1) Another sunny day! [said on an obviously sunny day]

(2) Wintry morning again. [said in the middle of December]

(3) Great view from here! You can see the whole city. [said on a hill from where an amazing view can be seen]

(4) The traffic in this city is always so chaotic! [said in a traffic jam]

(5) I do like a good cup of coffee before class. [said while two teachers are having a break before their next class]

(6) Oh, I really love these autumn days! [said in a mild autumn afternoon]

(7) Cute hairdo! [said when a speaker notices the hearer's new appearance]

(8) You always seem so busy! [said by a speaker who has seen the hearer working hard for a few days]

Laver $(1975,1981)$ labelled the former category neutral and the latter personal. Within the second category, he further distinguished between utterances alluding to the speaker, named self-oriented (5-6), and utterances alluding to the hearer, called other-oriented (7-8). These categories correspond to what Ventola (1979: 270-273) labelled indirect approaches, which refer to the communicative situation, and direct approaches, which refer to the hearer or to something related to him (his family, health, professional life, etc.). ${ }^{7}$ In Edmondson and House's terms, these two categories are known as remarks and discloses. Remarks are commonly banal and help the speaker to "[...] establish or increase familiarity with his hearer" because their content typically has to do with topics with which "[...] both speaker and hearer are assumed to be equally familiar [...]" (Edmondson and House 1981: 58). In contrast, discloses provide the hearer with information that the speaker "[...] believes [he] may be interested/amused, etc. to gain the acquaintance of, or further familiarity with, his person" (Edmondson and House 1981: 59). 
Regarding the content of phatic utterances, teachers could highlight that it appears to be about mutually known facts, events or things. Nevertheless, this straightforward, and somewhat simplistic, description would not suffice. Traditional misconceptions only lead many teachers to comment that what makes a topic a good candidate for phatic communion is its seeming obviousness or irrelevance. Undoubtedly, the phaticity of utterances and topics resides in the estimates of what can count as trivial or irrelevant, but only partially. Neither utterances nor topics can be taken to be inherently phatic, or likely be interpreted as such, only because they seem obvious to the speaker: the hearer's uptake needs to be taken into account. Therefore, phaticity must be presented as a constantly negotiable feature, upon which interlocutors make and revise decisions on the basis of cultural conventions about expectable topics or what can be talkable, and factors such as the spatio-temporal situation, the institutional nature of context, the conversational phase, the activity in which interlocutors are immersed and the frames they activate (Kasper 1984; Coupland et al. 1992; Coupland et al. 1994).

The influence of these conventions and factors can be observed, for example, in some communities, whose members find conventionally unacceptable very technical or personal topics like death, illness, sex or income, regardless of how intimate they are, and almost automatically prefer talking about safer topics such as the weather, their health or any matter about which they may have a similar opinion (Ventola 1979; Tannen 1984). Such conventions and factors also cause an often-phatic topic like the weather to lose its phaticity, if, for example, interlocutors are in a travel agency discussing possible destinations for their vacations, and the weather is a factor adding attractiveness (Coupland and Ylänne-McEwen 2000: 164). Similarly, questions about an individual's well-being may not be ritual but aimed at obtaining authentic information about his health, if made by a doctor (Coupland et al. 1992; Coupland et al. 1994). Finally, the influence of contextual factors and frames activated can 
turn a phatic remark like (9) into an indirect request to shut the window or turn the heater on (Kasper 1984):

(9) Oh, it is cold in here!

Schneider (1988: 84-86) shows that the information contained in the frames interlocutors activate and access highly conditions topic-selection in phatic communion. Its topic tends to be associated with elements of the immediate situation -i.e. the spatio-temporal scenario of a conversation- of the communicative situation or of the super-situation. To understand this, learners can imagine a group of university students at a disco, who make remarks about, for instance, the place, music, people, etc. If they are to engage in small talk, they can keep that initial frame activated and talk about its elements, or they can activate a more specific frame connected with any of them and comment on more specific details. If a more specific frame were activated, learners would shift to the communicative situation. Thus, if they talked about the people in the party, they could expand on this topic by further commenting on their clothes, dance partners, etc. However, learners may also opt for a more general frame that subsumes one or some of the elements of the immediate situation, such as life as university students, hobbies, leisure, etc. If students did this, they would move to the super-situation, which opens up a greater topic potential. Nevertheless, teachers must make it clear that preferences and priorities among distinct topics will depend on individuals' gender, age, interests, etc. (Schneider 1988: 86).

To wrap up this phase, teachers could test learners' perceptions of phaticity by centring on the likely effects of other speakers' remarks or discloses through multiple-choice exercises like the one below, in which learners could also comment on the rationale for their choices (Cohen 2010: 268-269):

\section{TABLE 3}

Additionally, learners could be trained to visualise the elements of frames in particular 
situations and think of the possible remarks they could make. They could also try to imagine which other frames they might access from the elements present in the frame(s) already activated. Thus, learners would practise how to link or change topics, become aware of different topical routes and exercise how to expand a conversation. Finally, learners could predict the topics other people might address depending on their age, sex, status, occupation, etc., and how they might shift from one topic to another.

\subsection{Reasoning about phatic discourse}

The fourth phase purports to make learners understand that choices of phatic utterances in the United Kingdom and the United States depend heavily on sociopragmatic factors. Therefore, learners will be assisted in reasoning out two crucial issues: (i) the interactive variables regulating the use of phatic tokens, i.e. with whom they can use them, and (ii) the implications that their usage may have, i.e. the consequences on evaluations of the (im)politeness of their communicative behaviour. This is probably the densest phase due to the different theoretical perspectives teachers may adopt to account for the latter issue.

Laver $(1975,1981)$ may be credited for one of the most noteworthy contributions to the study of phatic discourse, as he related its use in the United Kingdom and the United States to two variables: status and solidarity, or, in Brown and Levinson's (1987) terms, power and social distance. He observed the following tendencies:

(i) When interlocutors are socially equal and know each other (relatively) well, they indistinctively use neutral and personal phatic utterances. This situation represents a solidarity politeness system (Scollon and Wong-Scollon 1995).

(ii) When interlocutors do not know each other (well), regardless of whether there is a status difference, they tend to avoid personal utterances and select neutral ones. In this case, individuals interact in a deference politeness system (Scollon and Wong-Scollon 
1995).

(iii) When interlocutors' status differs, it determines individuals' choices. If a low-status subject addressees another of higher status, the inferior seems to use self-oriented phatic utterances and avoid other-oriented ones. On the contrary, when a high-status subject addresses a lower-status person, the higher can use other-oriented utterances and avoids self-oriented ones. This represents a hierarchical politeness system (Scollon and Wong-Scollon 1995).

Laver (1975: 224-225) also came to conclusions about the sociopragmatics of phatic utterances. If individuals select neutral or personal utterances in a solidarity system, they seem to maintain solidarity on the basis of topics with which they would be acquainted. On the other hand, if individuals in a deference system follow the tendency described, they will reciprocate some solidarity on the grounds of neutral topics at the same time they keep distant by not addressing personal topics. Finally, regarding the hierarchical system, there seems to be a tacit convention allowing the higher-status participant to invade the inferior's psychological space through other-oriented utterances and preventing the inferior from invading that of the superior by avoiding these utterances and using instead self-oriented ones. Thus, interlocutors appear to maintain and reinforce status differences.

Laver's $(1975,1981)$ observations could be a helpful aid to make learners reason about some of the communicative effects of phatic communion. They can be warned that erroneous choices in particular social contexts may have unwanted consequences not only on the relationship they wish to establish or maintain, but also on their addressees' perceptions of their personality, identity, attitudes, intentions or level of politeness. It is precisely this last issue that should next receive attention, so teachers may continue this phase by addressing the (im)politeness of phatic utterances in specific contexts.

Some teachers may argue that if learners follow the patterns so far described, their 
behaviour will be very likely assessed as polite. Although this may be true, it is only to some extent. If learners do not follow such patterns, their behaviour need not be evaluated as impolite, but may result in more complex effects. Although Laver's $(1975,1981)$ contribution may be a good starting point to account for some outcomes of phatic communion, it presents certain choices as acceptable or expectable in specific contexts. This might incite learners to assume that some L2 users could regard the same choices as advisable in given situations.

Learners must understand politeness as a pragmatic phenomenon aimed at avoiding interpersonal conflict or maintaining social harmony (Lakoff 1973; Leech 1983; Brown and Levinson 1987), but more importantly, as aimed at achieving a wide array of interactive goals which comprise projecting, managing and negotiating identities, roles, feelings and/or attitudes; adhering to cultural norms and expectations, or creating, maintaining, enhancing, modifying or destroying social relationships (Bou Franch and Garcés Conejos 2003; Mills 2003; Padilla Cruz 2006). In order to discuss the (im)politeness of phatic utterances, teachers may adopt some of the prominent approaches to politeness, whose postulates and viewpoints enact a complete understanding of the rationale of phatic communion.

\subsubsection{The conversational-maxim approach to phatic communion}

The conversational-maxim approach assumes the existence of norms other than the Cooperative Principle (Grice 1975), which explain why interlocutors apparently do not abide by it (Lakoff 1973; Leech 1983). Since phatic communion is often presented as scarcely informative (Abercrombie 1956; Turner 1973; Hudson 1980), it is considered a deviation from an admittedly accepted way of speaking that meets the standards of 'authentic' and 'efficient' communication (Coupland et al. 1992: 211; Coupland 2000: 7-8). More specifically, phatic utterances can be seen as violations of the maxim of quantity, as the speaker fails or is reluctant to offer an expected amount of information. If her 
uncooperativeness is evident, her behaviour is assessed as impolite.

Nevertheless, the use of phatic utterances may obey other conversational norms. Leech (1983) suggests the existence of the Phatic Maxim, which justifies why individuals do not always offer a satisfactory amount of information. It encourages individuals to "avoid silence", or to "keep talking" (Leech 1983: 141), and captures the intuition that individuals resort to phatic utterances to avoid the tension likely to originate from taciturnity. In turn, Schneider (1988) thinks that phatic discourse depends on two orientations people may adopt: politesse or formality, when interacting with strangers, and friendliness, typical of social events (Schneider 1988: 285). The former results in a distant style similar to that emanating from Lakoff's (1973) first rule of politeness -“Do not impose, keep the social distance"- and surfaces in the use of neutral phatic utterances. The latter yields a deferential style like that arising from Lakoff's (1973) second rule of politeness -“Offer options to the hearer"- and is manifested in the usage of personal phatic utterances. These two orientations yield two supermaxims:

(i) "Avoid offence" (politesse), which can be paraphrased as "Avoid everything negative" and regulates formal behaviour.

(ii) "Be friendly" (friendliness), which can be reworded as "Make your interlocutor feel good" and applies to friendly behaviour.

These two supermaxims are articulated in four more specific maxims referring to four interactive dimensions:

\section{TABLE 4}

On the grounds of this approach, teachers could explain that, if the use of phatic utterances is perceived to align with the imperatives captured in these maxims, learners' behaviour may be assessed as polite. Although this approach has some drawbacks due to the origin of maxims, their universality or culture-specificity, their ex post facto nature and 
interlocutors' awareness of them, it suggests the existence of some cultural knowledge and norms governing phatic communion and determining its assessments. Teachers could comment that such knowledge and norms need not be those leading learners (not) to use them in their L1.

\subsubsection{The face-saving approach to phatic communion}

Represented by Brown and Levinson's (1987) model, this approach presupposes a potential of aggressiveness in (non-)linguistic acts towards the face of interlocutors, so politeness consists of diminishing it in order to make communication smooth. This motivates individuals' behaviour in those cases in which they appear not to abide by the Cooperative Principle (Grice 1975).

Teachers may contend that small talk may threaten the hearer's negative face, as it would curtail the hearer's freedom of action, owing possibly to his willingness to remain silent or not to be bothered. Consequently, teachers warn learners that they can avoid risks by remaining silent. However, silence may also turn out to be troublesome due to its ambiguity. Although some communities regard it as a proper and expected behaviour in many situations -religious services, lectures, etc.- others see in it a sign of bad mood or shyness (Sifianou 1995: 100101). Silence would be a polite choice if the other individual does not speak since it might avoid virtual conflict and show consideration towards him if he is older or higher in status (Jaworski 1993: 25). Silence would also be polite when the speaker feels that what she intends to say could be interpreted as a sign of disapproval or disagreement (Sifianou 1995: 102).

But learners should also be conscious that if they fail to produce phatic tokens, they would be missing an excellent opportunity to attend to their interlocutor's positive face. Small talk has been considered to function as face-enhancing or face-boosting acts (Holmes 1988; Schneider 1988) contributing to solidarity, agreement and bonds of union (Lyons 1968; Silva 
1980; Leech 1983). Phatic utterances generally achieve these effects because they are positive-politeness strategies with which the speaker indicates that she treats the hearer as a person whose wishes, features and viewpoints she knows and admires, expresses her approval and personal interest in him, signals in-group membership, seeks agreement or establishes reciprocity and affinity as regards desires, intentions or preferences (Schneider 1988). Accordingly, if learners engage in small talk for these purposes, their behaviour may be judged as polite.

Encouraging learners to use phatic utterances for these reasons may nonetheless be problematic, as no communicative behaviour should be presented as face-enhancing or faceboosting by default. For instance, some hearers perceive phatic compliments (Boyle 2000) as threatening their negative face, if they do not know the complimenter (LewandowskaTomaszczyk 1989: 75; Sifianou 1997: 70). In countries like China or Poland, moreover, a complimentee may interpret them as attempts to influence subsequent behaviour, which would threaten his negative face and be impolite (Jaworski 1995). Arguing that phatic utterances automatically create solidarity or bonds of union is also controversial because their usage depends on a community's interactive norms. Learners must be alerted that some individuals use phatic utterances as a consequence of maxims like those of approbation or interest (Leech 1983). If phatic utterances are perceived as obeying those maxims, they will be interpreted as polite. Alternatively, if other individuals attach more importance to the maxim of modesty (Leech 1983), learners should be advised to avoid some phatic utterances, like compliments, so as not to be judged as impolite.

On the other hand, teachers should underline that not all types of phatic utterances function as positive-politeness strategies. Personal phatic utterances may certainly be taken to act as positive-politeness strategies fostering intimacy and social proximity in solidarity systems. In contrast, neutral phatic utterances would work as negative-politeness strategies 
seeking independence and social distancing in non-solidarity systems. But these connections would not always be stable. Neutral and self-oriented phatic utterances may contribute to solidarity and intimacy in non-solidarity systems on the basis of uncontroversial topics safeguarding the hearer's privacy, so they could function as positive-politeness strategies. In contrast, in hierarchical relations, the use of other-oriented utterances by the superior and of self-oriented utterances by the inferior strengthen status differences and could therefore act as negative-politeness strategies aimed at safeguarding privacy. If the superior used self-oriented utterances, she would be offering solidarity, even if temporarily, so these utterances would in this case behave as positive-politeness strategies.

Accounting for the (im)politeness of phatic utterances from this approach must make it clear that their values and consequences are contingent on context. This sensitises learners to the importance of other interlocutors' identities and roles, and empowers them to make informed decisions as to whether or not resort to small talk, what to say, when and to whom on the basis of the interactive effects they want to achieve.

\subsubsection{The contextual-appropriateness approach to phatic communion}

Finally, this approach claims that interlocutors hold a set of beliefs about their sociality rights and obligations, as well as their interactional goals. Such beliefs, some of them negotiable, determine what is allowed or expected from them, making up some sort of conversational contract (Fraser and Nolen 1981; Spencer-Oatey 2008). Accordingly, to be polite amounts to abiding by that contract, whose terms are the yardstick to assess (im)politeness (Fraser and Nolen 1981: 96).

Since (im)politeness is a matter of (in)appropriateness to a given context defined by contractual terms, teachers should underscore that no type of phatic utterance is inherently (im)polite. Evaluations of (im)politeness will be contingent on the perceived (in)adequacy of 
utterances to the interactive context. However, learners might wonder how to determine that context and what the very concept of appropriateness amounts to.

As for social context, teachers must remind learners that politeness systems are demarcated by the psycho-social variables power and distance (Brown and Levinson 1987). These also determine their sociality rights and obligations and are crucial to making decisions about the type of phatic utterances learners can select and their topics in specific systems. Therefore, some types of phatic utterances may be expected or permitted -polite- whilst others may be dispreferred or ruled out -impolite.

Regarding appropriateness, teachers should make it clear that it is "[...] something which individuals formulate themselves in order to judge others' and their own utterances" (Mills 2003: 70). Although appropriateness highly depends on the cultural norms individuals abide by and their perception of the social context, such formulation could also be troublesome: it could presuppose certain homogeneity in L2 speakers' universe of beliefs and subsequent communicative behaviour when engaging in small talk. Instead, appropriateness should be presented as an extremely relative or negotiable notion, which may vary slightly or drastically across individuals or communities so that what can be perfectly adequate to one individual or community in a given situation may not be acceptable to (an)other(s). Appropriateness then depends on factors such as individuals' status, social closeness, identity, ethnic origin, groupaffiliation, age, role within the group, personality, mood, etc. But more importantly, appropriateness is contingent on individuals' interactive goals. Although these goals comprise the establishment or maintenance of a certain relationship, they may also include the (radical) redefinition of an already existing relationship.

This conceptualisation can help account for what may happen with some types of apparently dispreferred phatic utterances in specific contexts: far from being impolite, they must be interpreted as attempts to (temporarily) modify certain aspects of the existing 
relationship. Accordingly, in a deferential relationship a self-oriented utterance needs not be impolite, but may be aimed at achieving solidarity. As a result, teachers should ensure that learners understand that the appropriateness of phatic utterances

[...] is something which each individual has to work out, by assessing their own status in relation to other participants in the community of practice, and by assessing what they think the context demands. This means that they constantly have to assess their own position and identity/role within the group in order to evaluate what is appropriate for them and others, and to assess whether they are going to abide by these rules or flout them. (Mills 2003: 71)

Drawing from this approach, teachers would ensure an awareness of the (im)politeness of phatic utterances as a by-product of a thorough evaluation of a wide variety of factors defining interactive contexts and the selection of linguistic expressions that best match them and contribute to the achievement of interactive goals. Behaving politely may not merely be a question of expressing deference or affiliation but, more importantly, knowing how to strategically use certain linguistic means in distinct communicative circumstances to fulfil specific intentions. Thus, teachers will enact an understanding of (im)politeness as “[...] akin to resources which are viewed differently by interactants and which may be drawn on by them to different extents because of their assessments of their position of local and institutional power relative to others, and because of the way that they themselves are treated by others" (Mills 2003: 109).

This instructional phase can be wrapped up with some metapragmatic tasks testing how well learners think someone else performs pragmatically (Cohen 2010: 267). Learners can be asked to read different interactive contexts and then choose from among a number of possible phatic utterances, only one of which fits appropriately in each context. An example could be the following multiple-choice, which could be completed by having the learners add the 
rationale for their choices:

\section{TABLE 5}

Additionally, learners may rank possible phatic utterances for one context from the most to the least appropriate and verbalise the rationale of their decisions, discussing whether they perceive some potential threat to their interlocutors and themselves (Cohen 2010: 268):

\section{TABLE 6}

Finally, learners may also be given a list of different phatic utterances collected from naturally-occurring interaction in order to elicit the most appropriate politeness system(s) where they could be used by considering the sociopragmatic factors previously mentioned. Once the context has been provided, the teacher should explain the actual context in which utterances were found and discuss whether learners' guesses might turn out to be appropriate or not, and why.

\subsection{Rehearsing phatic discourse}

Throughout the previous phases learners might have gained substantial knowledge about phatic discourse, which they should be able to put into practice by means of various communicative tasks. Undoubtedly, productive practice is one of the necessary conditions for learning to take place (Swain 1998). Following Martínez Flor and Usó Juan (2006), this phase includes both controlled and free oral and written activities, which put learners under some pragmatic pressure and enable teachers to collect data of their performance and test their knowledge.

Regarding controlled oral production activities, one that could work well is to play a video containing (an) example(s) of phatic discourse. Right at the moment the phatic token is to appear, the scene is paused and learners complete the following video worksheet to make them reflect on the phatic utterance(s) likely to appear in that context: 


\section{TABLE 7}

Having filled the worksheet, learners act out in pairs a role-play where they show how they think the conversation could follow. Another useful task could be to ask learners to act out role-plays in contexts corresponding to different politeness systems so that they have to decide the appropriate type and content of phatic utterance(s):

\section{TABLE 8}

As for controlled written activities, learners could complete contextualised gapped sentences that call for specific types of phatic utterances. This enables teachers to see if they are aware of the influence of sociopragmatic factors and can control an inventory of (formulaic) phatic tokens (Cohen 2010: 278):

\section{TABLE 9}

Additionally, learners could produce written responses to Discourse Completion Tests (DCTs). Despite their disadvantages (Garcés-Conejos Blitvich 2006), DCTs may reflect what they would say in given situations and elicit awareness of what other individuals might say depending on sociocultural factors (Cohen 2006). Such DCTs could also call for more than two turns by both speaker and listener so as to reflect turn-taking (Cohen 2010: 274-277):

\section{TABLE 10}

Finally, learners could be requested to analyse sample dialogues, emails or letters which contain examples of phatic communion, observing language carefully to determine the influence of sociopragmatic factors and the level of politeness. Then, they could produce similar dialogues, emails or letters in the L2 in imagined situations and contrast their own language with that in the sample dialogues.

Concerning free oral tasks, it would be desirable to get data of learners' performance in non-elicited situations and out of the class. Difficult though this may be, learners could be asked to record authentic face-to-face interactions with native speakers or between themselves 
in order to achieve a specific goal (Kasper 1997; Martínez Flor and Usó Juan 2006). As Cohen (2010: 270) suggests, this can be done as part of a speaking portfolio. If recordings are done in class, learners could rehearse what they would say because "Their minds may need to get going in the target language first" (Cohen 2010: 270). Alternatively, learners could use video-conferencing programmes, which easily facilitate opportunities to interact and negotiate meaning online with native speakers, other non-native speakers, tutors or instructors. Despite its technological challenges and the anxiety it might cause to some learners, videoconferencing can be an optimal vehicle for intercultural communication and enable learners to notice the real use of contextualised phatic discourse owing to immediacy and real-time communication (Gillies 2008; Ishihara 2010b: 253-254; Sardegna and Molle 2010: 286-287).

As for free written tasks, these may rely on computer-mediated communication (CMC), such as postings on blogs, emails or conversations in chat-rooms or educational forums. Asynchronous tools like postings on blogs and emails avoid the anxiety that speaking in public may cause some learners. They also allow learners to carefully edit their written production, organise linguistic data under different 'threads' or subject lines, or analyse the phatic language they and others use. Thus, they can create some sort of database of samples to which they can subsequently resort (Ishihara 2010b). Furthermore, despite the dangers inherent to the use of email -e.g. introducing conventions typical of oral discourse, impossibility to rectify misunderstandings or to negotiate phaticity, etc.- emails offer students excellent opportunities to take chances they might not otherwise take in face-to-face conversations (Bloch 2002: 118-121).

Synchronous CMC tasks can be more interactive, as they engage learners in more extended and concurrent interaction where they can negotiate phaticity. As Ishihara (2010b: 254) points out, learners could take advantage of conversations in chat-rooms or educational forums in order to observe authentic cases of phatic language, interview competent L2 
speakers about the use of phatic tokens or their perception and exchange their own analyses and impressions of pragmatic-focused observations. However, learners should be alerted to some of the inherent peculiarities of this kind of interaction regarding differences in turntaking, overlapping, delays, gaps, breaks, restricted repertoire or the rather innovative ways to express politeness (Kulkarni 2011).

\subsection{Revising learners' performance}

To conclude, it is necessary to revise the outcome of the different activities assigned and offer feedback related to performance. Feedback must centre on learners' both productive and receptive abilities. Thus, learners gain the three necessary conditions for the acquisition of pragmatic ability in the target language: namely, exposure to input, opportunities for generating output and feedback.

For feedback to be as complete as possible, teachers should base their assessments of performance on criteria matching the instructional goals consistently. According to Ishihara (2010c: 293-295), teachers should take into account pragmalinguistic issues such as:

- To what extent do learners understand phatic discourse as intended by other speakers?

- How is learners' phatic discourse most likely interpreted by L2 interlocutors?

- To what extent is learners' phatic language effective in conveying and accomplishing their intentions?

Bearing this in mind, teachers should (i) analyse learners' vocabulary, formulaic phrases, grammatical structures, strategies for phatic communion and ability to engage in extended phatic sequences, and (ii) comment on their tone of voice, gestures, etc. In addition, teachers should consider sociopragmatic issues such as:

- To what extent do learners understand the use of phatic discourse in the L2 and its likely consequence in the cultural and situational context? 
- How are their intentions interpreted by L2 speakers?

- What consequences might arise from learners' phatic discourse in the L2 community? Accordingly, teachers should comment on the appropriateness of learners' phatic discourse to a given context, by paying attention to (i) their level of directness, formality and politeness, and (ii) learners' adherence to and handling of L2 cultural norms or ideologies.

Teachers must not forget that learners might not wish to model themselves after native speakers or follow particular L2 norms, but behave uniquely so as to preserve their own identities. For this reason, feedback should not be aimed exclusively at correcting learners, but should respect their intentions and support them in the achievement of their goals by giving adequate information. It is therefore important that teachers and learners work together in examining the subtle nuances that they may express either intentionally or unintentionally when engaging in phatic communion so that learners are actually helped both to avoid transmitting unwanted messages and to accurately interpret small talk (Ishihara 2010c: 302).

\section{Conclusion}

The development of pragmatic competence is extremely important when teaching and learning an L2. A deficient or incomplete mastery of pragmalinguistic and sociopragmatic aspects of L2 areas, such as phatic discourse, may lead learners to make unfortunate mistakes that might ultimately have negative consequences on social relationships and the perception that other individuals might have of their identities and personalities. For this reason, this paper has suggested a series of pedagogical phases to deal with phatic discourse in the English class. Although these phases are inspired on the approach developed by Martínez Flor and Usó Juan (2006), they have been adapted to fit the object of teaching and based on relevant contributions and findings from various disciplines. This methodological proposal seeks to raise learners' meta-pragmatic awareness by combining explicit and implicit 
treatment of phatic communion, which facilitate learners' noticing of relevant features, deduction of underlying norms and understanding of how it works in the target community. Thus, this proposal aims to endow learners with the necessary tools that enable them to manage phatic discourse efficiently in order to satisfactorily interact and achieve their communicative goals. In addition, by including different tasks focused on both pragmalinguistic and sociopragmatic aspects of phatic discourse this proposal purports to give learners opportunities for output so that they can put into practice their knowledge and realise possible additional or persistent deficits as they communicate and negotiate meaning.

This proposal differs from others in that it seeks to offer an all-encompassing treatment of different manifestations of phatic communion, ranging from tokens typically occurring at the fringes of conversations to extended phatic sequences, and issues such as topic-selection, the usage of phatic utterances and their (im)politeness. Regarding the last one, this proposal bases pedagogical intervention on three well-known approaches in order to gain a more complete understanding of the effects that linguistic behaviour may have and the factors determining its assessment. Another feature that differentiates this proposal is its inclusion of precise guidelines to assess learners' awareness of pragmalinguistic and sociopragmatic aspects (Cohen 2010; Ishihara 2010c) and thus give them detailed and helpful feedback about their performance.

Devised for learners with at least a B1 level, this proposal could be applied at the beginning of courses, when materials and instructors usually focus on social rituals like introductions. Since phatic communion is connected with the interactional side of communication and relates to everyday experiences, commonalities and social niceties, its treatment at the initial stage could motivate learners and make them confident enough to use the target language. Also, its treatment at that point can provide learners with resources that can be subsequently used to compensate for linguistic deficits in other L2 areas. Although 
issues such as types of learners, disparity in proficiency levels or class dynamics are not specifically considered, the activities included in this proposal allow for different groupings of learners depending on their level and needs so that if less proficient learners work with more proficient ones, the chances that they improve in terms of both knowledge of and performance in phatic communion will also increase (Kasper and Rose 2002). However, the activities in this proposal are mainly centred on productive skills. Although some exercises work with receptive ones, this proposal does not pay due attention to some cognitive issues related to the interpretation of discourse or utterances as phatic or how learners may cause the effects associated with phatic communion. These are issues which, owing to space limitations, should be developed in a more extended proposal. 


\section{Notes}

1. See Padilla Cruz (in press) for references to works on pragmatic failure when learners accomplish various speech acts.

2. Nevertheless, some of the deviating features of the small talk of these Mexican learners were sometimes motivated by an intentional engagement in language play.

3. Reference to proficiency levels is made in accordance with the Common European Framework of Reference for Languages, which distinguishes six levels: A1 (elementary), A2 (beginner), B1 (intermediate), B2 (upper-intermediate), C1 (advanced) and C2 (proficiency).

4. For a debate on specific aspects of this methodology, see Garcés-Conejos Blitvich (2006) and Cohen (2006).

5. In fact, in informal surveys I normally find that most of my first-, second- and third-year undergrads doing English Philology, English Studies or other programmes have no idea what this term alludes to, nor have they even heard of it.

6. See Padilla Cruz (2004) for a discussion about how this information is inferred.

7. Approaches are utterances that seek to establish "[...] comfortable relationships with others", so they address "[...] safe topics, social niceties [...]" (Ventola 1979: 273).

\section{Word count: 8898 words}




\section{References}

Abercrombie, David. 1956. Problems and principles. London: Longman.

Alcón Soler, Eva. 2005. Does instruction work for learning pragmatics in the EFL context? System 33(3). 417-435.

Bloch, Joel. 2002. Student/teacher interaction via email: The social context of Internet discourse. Journal of Second Language Writing 11(2). 117-134.

Bou Franch, Patricia and Pilar Garcés Conejos. 2003. Teaching linguistic politeness: A methodological proposal. International Review of Applied Linguistics in Language Teaching 41(1). 1-22.

Boyle, Ronald. 2000. 'You worked with Elizabeth Taylor!' Phatic functions and implicit compliments. Applied Linguistics 21(1). 26-46.

Brown, Penelope and Stephen C. Levinson. 1987. Politeness. Some universals in language usage. Cambridge: Cambridge University Press.

Burnard, Philip. 2003. Ordinary chat and therapeutic conversation: Phatic communication and mental health nursing. Journal of Psychiatric and Mental Health Nursing 10(6). 678682.

Capel, Annette and Wendy Sharp. 2002. Objective Proficiency. Cambridge: Cambridge University Press.

Clandfield, Lindsay. 2006. Straightforward. Elementary student's book. Oxford: Macmillan.

Clandfield, Lindsay. 2007. Straightforward. Beginner student's book. Oxford: Macmillan.

Clennell, Charles. 1999. Promoting pragmatic awareness and spoken discourse skills with EAP classes. ELT Journal 53(2). 83-91.

Cohen, Andrew D. 2005. Strategies for learning and performing L2 speech acts. Intercultural Pragmatics 2(3). 275-301.

Cohen, Andrew D. 2006. Interlanguage pragmatics: A reply to Pilar Garcés-Conejos Blitvich. 
Intercultural Pragmatics 3(3). 359-364.

Cohen, Andrew D. 2010. Approaches to assessing pragmatic ability. In Noriko Ishihara and Andrew D. Cohen, Teaching and learning pragmatics. Where language and culture meet, 264-285. Harlow: Pearson Education.

Coupland, Justine (ed.). 2000. Small talk. Harlow: Pearson Education.

Coupland, Justine, Nikolas Coupland and Jeffrey D. Robinson. 1992. How are you? Negotiating phatic communion. Language in Society 21(2). 207-230.

Coupland, Justine, Jeffrey D. Robinson and Nikolas Coupland. 1994. Frame negotiation in doctor-elderly patient consultations. Discourse and Society 5(1). 89-124.

Coupland, Nikolas and Virpi Ylänne-McEwen. 2000. Talk about the weather: Small talk, leisure talk and the travel industry. In Justine Coupland (ed.), Small Talk, 163-182. Harlow: Pearson Education.

Cunningham, Gillie and Jon Bell. 2009. Face2face advanced. Cambridge: Cambridge University Press.

Dellar, Hugh and Andrew Walkley. 2010. Outcomes. Upper intermediate. Andover: Heinle.

Dellar, Hugh and Andrew Walkley. 2012. Outcomes. Advanced. Andover: Heinle.

Duda, Richard and Chantal Parpette. 1987. Les échanges phatiques en langue étrangère. In Hoda Blanc, Michèle Le Douaron and Daniel Véronique (eds.), S'approprier une langue étrangère... Actes du VI Colloque International «Acquisition d'une Langue Étrangère: Perspectives et recherches », 82-87. Paris: Didier Érudition.

Edmondson, Willis and Juliane House. 1981. Let's talk and talk about it. A pedagogic interactional grammar of English. München: Urban \& Schwarzenberg.

Fraser, Bruce and William Nolen. 1981. The association of deference with linguistic form. International Journal of the Sociology of Language 27. 93-109. 
Garcés-Conejos Blitvich, Pilar. 2006. Interlanguage pragmatics: A response to Andrew Cohen's "Strategies for learning and performing L2 speech acts" published in Vol. 2, No. 3, of Intercultural Pragmatics. Intercultural Pragmatics 3(2). 213-223.

Gillies, Donald. 2008. Student perspectives on videoconferencing in teacher education at a distance. Distance Education 29(1). 107-118.

Goldstein, Ben. 2005. Framework. Level 3. London: Richmond.

Grice, Herbert P. 1975. Logic and conversation. In Peter Cole and Jerry Morgan (eds.), Syntax and semantics vol. 3: Speech acts, 41-59. New York: Academic Press.

Hobbs, Martyn and Julia Starr Keddle. 2006. Get real. Student's book. Helbling Languages.

Hobbs, Martyn and Julia Starr Keddle. 2008. Get real. Student's book and workbook. Helbling Languages.

Hoey, Michael. 1991. Some properties of spoken discourses. In Roger Bowers and Christopher J. Brumfit (eds.), Applied linguistics and English language teaching, 65-85. Basingstoke: Macmillan.

Holmes, Janet. 1988. Paying compliments: A sex-preferential positive politeness strategy. Journal of Pragmatics 12. 445-465.

Holmes, Janet. 2000. Doing collegiality and keeping control at work: Small talk in government departments. In Justine Coupland (ed.), Small talk, 32-61. Harlow: Pearson Education.

Hudson, Richard A. 1980. Sociolinguistics. Cambridge: Cambridge University Press.

Ishihara, Noriko. 2010a. Collecting data reflecting the pragmatic use of language. In Noriko Ishihara and Andrew D. Cohen, Teaching and learning pragmatics. Where language and culture meet, 37-55. Harlow: Pearson Education. 
Ishihara, Noriko. 2010b. Incorporating technology into pragmatics-focused instruction. In Noriko Ishihara and Andrew D. Cohen, Teaching and learning pragmatics. Where language and culture meet, 244-263. Harlow: Pearson Education.

Ishihara, Noriko. 2010c. Assessment of pragmatics in the classroom. In Noriko Ishihara and Andrew D. Cohen, Teaching and learning pragmatics. Where language and culture meet, 286-317. Harlow: Pearson Education.

Ishihara, Noriko and Andrew D. Cohen. 2010. Teaching and learning pragmatics. Where language and culture meet. Harlow: Pearson Education.

Jaworski, Adam. 1993. The power of silence: Social and pragmatic perspectives. London: Sage Publications.

Jaworski, Adam. 1995. 'This is not an empty compliment!' Polish compliments and the expression of solidarity. International Journal of Applied Linguistics 5(1). 63-94.

Kasper, Gabriele. 1984. Pragmatic comprehension in learner-native speaker discourse. Language Learning 34(1). 1-20.

Kasper, Gabriele. 1997. Can pragmatic competence be taught? (NetWork \#6) [HTML document]. Honolulu: University of Hawai'i, Second Language Teaching \& Curriculum Center. http://www.nflrc.hawaii.edu/NetWorks/NW06/ (accessed 5 November 2011)

Kasper, Gabriele and Kenneth R. Rose (eds.). 1993. Pragmatics in language teaching. Cambridge: Cambridge University Press.

Kasper, Gabriel and Kenneth R. Rose. 2002. Pragmatic development in a second language. Malden, MA: Blackwell.

Kasper, Gabriel and Richard Schmidt. 1996. Developmental issues in interlanguage pragmatics. Studies in Second Language Acquisition 18(2). 149-169.

Kaur, Jagdish. 2011. Intercultural communication in English as a lingua franca: Some sources of misunderstanding. Intercultural Pragmatics 8(1). 93-116. 
Kenny, Nick, Peter Sunderland and Jane Barnes. 2002. New Proficiency pass key. Oxford: Macmillan.

Kerr, Philip. 2006. Straightforward. Pre-intermediate student's book. Oxford: Macmillan.

Kerr, Philip and Ceri Jones. 2006. Straightforward. Intermediate student's book. Oxford: Macmillan.

Kerr, Philip and Ceri Jones. 2007. Straightforward. Upper-intermediate student's book. Oxford: Macmillan.

Kondo, Sachiko. 2008. Effects of pragmatic development through awareness-raising instruction: Refusals by Japanese EFL learners. In Eva Alcón Soler and Alicia Martínez Flor (eds.), Investigating pragmatics in foreign language learning, 153-177. Bristol: Multilingual Matters.

Kulkarni, Dipti. 2011. Phatic communion on instant messaging: A conversation analytic approach. Paper presented at the $12^{\text {th }}$ International Pragmatics Conference, University of Manchester, 3-8 July.

Ladegaard, Hans J. 2011. Negotiation style, speech accommodation, and small talk in SinoWestern business negotiations: A Hong Kong case study. Intercultural Pragmatics 8(2). 197-226.

Lakoff, Robin T. 1973. The logic of politeness; or, minding your p's and q's. In Claudia Corum, T. Cedric Smith-Stark and Ann Weiser (eds.), Papers from the Ninth Regional Meeting, 292-305. Chicago, IL: Chicago Linguistic Society.

Laver, John. 1975. Communicative functions of phatic communion. In Adam Kendon, Richard M. Harris and Mary R. Key (eds.), Organisation of behaviour in face-to-face interaction, 215-238. The Hague: Mouton.

Laver, John. 1981. Linguistic routines and politeness in greeting and parting. In Florian Coulmas (ed.), Conversational routine. Explorations in standardized communication 
situations and prepatterned speech, 289-304. The Hague: Mouton.

Leech, Geoffrey. 1983. Principles of pragmatics. London: Longman.

Lewandowska-Tomaszczyk, Barbara. 1989. Praising and complimenting. In Wieslaw Oleksy (ed.), Contrastive pragmatics, 73-100. Amsterdam: John Benjamins.

Lyons, John. 1968. Introduction to theoretical linguistics. London: Cambridge University Press.

Malinowski, Bronislaw K. 1923. The problem of meaning in primitive languages. In Charles K. Ogden and Ivor A. Richards (eds.), The meaning of meaning. A study of the influence of language upon thought and of the science of symbolism, 451-510. New York: Harcourt, Brace \& Company, INC.

Martínez Flor, Alicia and Esther Usó Juan. 2006. A comprehensive pedagogical Framework to develop pragmatics in the foreign language classroom: The 6Rs approach. Applied Language Learning 16(2). 39-64.

Mills, Sara. 2003. Gender and politeness. Cambridge: Cambridge University Press.

Mugford, Gerry. 2011. Creating resources in foreign-language phatic communion. Paper presented at the $12^{\text {th }}$ International Pragmatics Conference, University of Manchester, 3-8 July.

Norris, Roy. 2008. Straightforward. Advanced student's book. Oxford: Macmillan.

O'Dell, Felicity and Annie Broadhead. 2008. Objective CAE. $2^{\text {nd }}$ Edition. Cambridge: Cambridge University Press.

Padilla Cruz, Manuel. 2004. Aproximación pragmática a los enunciados fáticos. Enfoque social y cognitivo. Sevilla: Universidad de Sevilla.

Padilla Cruz, Manuel. 2006. Hacia una nueva definición de la cortesía. In José L. Blas Arroyo, Manuela Casanova Ávalos and Mónica Velando Casanova (eds.), Discurso y sociedad. Contribuciones al estudio de la lengua en contexto social, 699-710. Castellón 
de la Plana: Publicacions de la Universitat Jaume I.

Padilla Cruz, Manuel. In press. Understanding and overcoming pragmatic failure in intercultural communication: From focus on speakers to focus on hearers. International Review of Applied Linguistics in Language Teaching.

Pavlidou, Theodossia S. 1994. Contrasting German-Greek politeness and the consequences. Journal of Pragmatics 21. 487-511.

Placencia, María Elena. 2004. Rapport-building activities in corner-shop interactions. Journal of Sociolinguistics 8(2). 215-245.

Redston, Chris and Gillie Cunningham. 2006. Face2face intermediate. Cambridge: Cambridge University Press.

Redston, Chris and Gillie Cunningham. 2007. Face2face upper-intermediate. Cambridge: Cambridge University Press.

Rose, Kenneth R. 1997. Pragmatics in the classroom: Theoretical concerns and practical possibilities. In Lawrence F. Bouton (ed.), Pragmatics and language learning 8, 267-295. Urbana: University of Illinois at Urbana-Champaign.

Rosnow, Ralph L. 1977. Gossip and marketplace psychology. Journal of Communication 27(1). 158-163.

Safont Jordá, María Pilar 2005. Third language learners. Pragmatic production and awareness. Clevedon: Multilingual Matters.

Sardegna, Veronica G. and Daniella Molle. 2010. Videoconferencing with strangers: Teaching Japanese EFL students verbal backchannel signals and reactive expressions. Intercultural Pragmatics 7(2). 279-310.

Schegloff, Emanuel A. 1972. Sequencing in conversational openings. In John J. Gumperz and Dell Hymes (eds.), Directions in sociolinguistics: The ethnography of communication, 346-380. New York: Holt, Rinehart and Winston. 
Schegloff, Emanuel A. and Harvey Sacks. 1973. Opening up closings. Semiotica 8. 289-327.

Schneider, Klaus P. 1988. Small talk. Analysing phatic discourse. Marburg: Hitzeroth.

Scollon, Ron and Suzanne Wong-Scollon. 1995. Intercultural communication. A discourse approach. Cambridge: Blackwell.

Sifianou, Maria. 1995. Do we need to be silent to be extremely polite? Silence and FTAs. International Journal of Applied Linguistics 5(1). 95-110.

Sifianou, Maria. 1997. Silence and politeness. In Adam Jaworski (ed.), Silence. Interdisciplinary perspectives, 63-84. Berlin: Mouton de Gruyter.

Silva, Omar. 1980. Phatic language: A preliminary contrastive analysis between English and Spanish. Lenguaje y Ciencias 20. 105-112.

Soars Liz, John Soars, Mike Sayer and Peter May. 2005. New Headway upper intermediate. Oxford: Oxford University Press.

Spencer-Oatey, Helen (ed.). 2008. Culturally speaking. Culture, communication and politeness. London: Continuum.

Stempleski, Susan, Nancy Douglas, James R. Horgan and Kristin L. Johansen. 2007. World pass. Boston: Thomson.

Sun, Hao. 2004. Opening moves in informal Chinese telephone conversations. Journal of Pragmatics 36. 1429-1465.

Swain, Merrill. 1998. Focus on form through conscious reflection. In Catherine Doughty and Jessica Williams (eds.), Focus on form in classroom second language acquisition, 64-81. Cambridge: Cambridge University Press.

Tannen, Deborah. 1984. The pragmatics of cross-cultural communication. Applied Linguistics 5(3). 188-195.

Thomas, Jenny. 1983. Cross-cultural pragmatic failure. Applied Linguistics 4(2). 91-112.

Tite, Paola, Martyn Hobbs and Julia Starr Keddle. 2008. Get real. Student's book. Helbling 
Languages.

Tomlinson, Brian. 1994. Pragmatic awareness activities. Language Awareness 3(3-4). 119124.

Turner, George W. 1973. Stylistics. Harmondsworth: Penguin.

Usó Juan, Esther and Alicia Martínez Flor. 2008. Teaching learners to appropriately mitigate requests. ELT Journal 62(4). 349-357.

Ventola, Eija. 1979. The structure of casual conversation in English. Journal of Pragmatics 3. 267-298. 
Tables

Table 1: L1/L2 Data-collection Worksheet

\begin{tabular}{|c|}
\hline L1/L2 Data-collection Worksheet \\
\hline 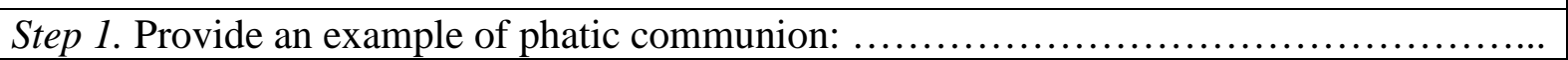 \\
\hline Step 2. Think about: \\
\hline 1. Interlocutors' age and gender: ................... \\
\hline 2. Interlocutors' role-relationship in conversation: \\
\hline 3. Interlocutors' occupation: ....................... \\
\hline 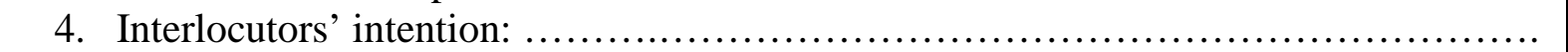 \\
\hline Step 3. At which conversational phase did this example occur? $\ldots \ldots \ldots \ldots \ldots \ldots \ldots \ldots \ldots \ldots$ \\
\hline Step 4. Describe the context where interlocutors where speaking: $\ldots \ldots \ldots \ldots \ldots \ldots \ldots \ldots \ldots \ldots$ \\
\hline $\begin{array}{l}\text { Step 5. Comment on tone, gestures, body-position, eye-contact, body-contact, physical } \\
\text { spatial distance } / \text { closeness: } \ldots \ldots \ldots \ldots \ldots \ldots \ldots \ldots \ldots \ldots \ldots \ldots \ldots \ldots \ldots \ldots \ldots \ldots \ldots \ldots \ldots \ldots \ldots\end{array}$ \\
\hline
\end{tabular}

Table 2: Awareness-raising Questions Worksheet

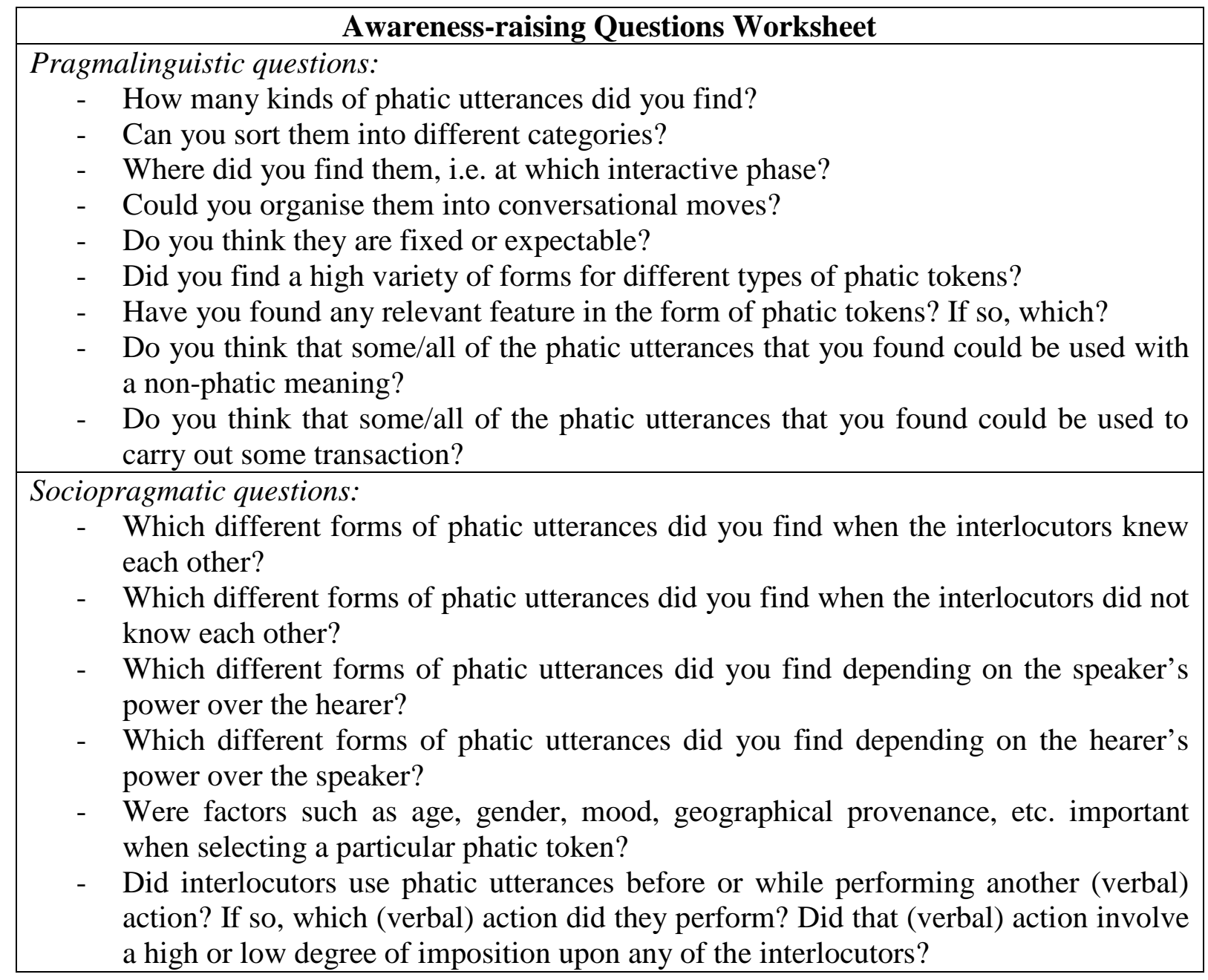

Table 3: Multiple-choice testing learners' perceptions of phaticity 
Henry and John are close friends. They are strolling around the city before having dinner at a restaurant. They are walking down a street where a bike lane has recently been built. Henry knows that John thinks that bike lanes are an optimal solution to traffic problems in the city, but that the way in which this particular one has been constructed is quite problematic and dangerous, as it runs over a great part of the pavement. They have talked about this issue several times. As they are heading for the restaurant, Henry makes the following remarks: "Oh my! I hate the way they built this bike lane. It is so dangerous! Cyclists can run you over!" How likely is John to consider Henry's remarks phatic?

a) Very likely.

b) Somewhat likely.

c) Not very likely.

What is the rationale for your choice?

Table 4: Schneider's maxims regulating small talk

\begin{tabular}{|l|l|l|}
\hline & Politesse - "Avoid offence" & Friendliness - "Be friendly" \\
\hline 1. Discourse & Avoid silence & Say something nice \\
\hline 2. Person & Avoid curiosity & Show interest in the hearer \\
\hline 3. Union & Avoid conflict & Create ties of union \\
\hline 4. Emotion & Avoid pessimism & Be optimistic \\
\hline
\end{tabular}

Table 5: Multiple-choice task testing learners' perceptions of other individual's performance.

A friend of yours is at a bus stop. Next to him is an unknown old lady. The bus is late and they are the only people at the stop. They are sitting close together and your friend decides to chat with the old lady. What would be the most appropriate remark to begin a conversation in this situation?
a) What a wonderful shirt you are wearing!
b) The bus seems to be late.
c) Greece's current economic situation is really worrying.
d) Are you going to the city centre?

Table 6: Ranking phatic utterances depending on appropriateness 
Your friend Peter meets his boss over coffee-break at the office. Although they hardly know each other, Peter knows the boss loves football and is a supporter of Manchester United. So, Peter addresses him with the following phatic remark: "Manchester United played a great match yesterday!" How (in)appropriate/(im)polite would you regard his remark?

1 Very appropriate/polite

2 Appropriate/polite

3 Inappropriate/impolite

4 Very inappropriate/impolite

Do you think Peter's remark might involve some threat to his boss or to himself? If so, explain which and why:

\section{Table 7: Video Worksheet}

\section{Video Worksheet}

Step 1. Circle the option you think is appropriate:

1. Speakers' social distance: close distant very distant

2. Speakers' power: $\mathrm{S}>\mathrm{H} \quad \mathrm{H}<\mathrm{S} \quad \mathrm{S}=\mathrm{H}$

Step 2. Provide information about the context where the characters are interacting.

Step 3. Provide additional aspects regarding their non-verbal behaviour (tone of voice, body language, attitudinal behaviour, facial expressions, etc.)

Table 8: Instructions for role-playing

You have been ill and therefore could not attend class over the past week. You have not got class notes and exams are approaching. You decide to ask your classmate Lisa, whom you know very well, to borrow her notes. But before actually requesting her notes, you do some chit-chat. Role-play a conversation where you show what you think you would say.

Table 9: Example of gapped sentence

Your new boss comes into the meeting-room. He is wearing a very elegant tie. After greeting him, you say: tie! I really like it! 
Table 10: example of DCT

You have run out of salt and need some for cooking dinner. You go to your neighbour's apartment in order to ask her for some. Before asking for it, you engage in some small talk.

Neighbour: Hi Jane! How are you doing?

You:

Neighbour: Good! I was about to have dinner.

You: 